\title{
Assessment of Predisposing Factors for Joint Contracture among Patients with Burn at One of the Governmental University Hospitals
}

\author{
Ahmed Abdelmaksoud Hegazy1, Susan Attia1, Zeinab Mohamed El-Sayed1, Moustafa \\ Ahmed2 \\ 1Medical-Surgical Nursing Department, Faculty of Nursing, Cairo University-Egypt \\ 2 General Surgery Department, Faculty of Medicine, Cairo University-Egypt
}

\begin{abstract}
Background: Burn is a serious health problem globally. Every year more than 300, 000 people die from fires only and millions of people are disabled and disfigured by severe burns. Survivors of burns often lead to a life complicated not only by the physical consequences of the burns, but also by stigma and discrimination related to the disability and disfigurement. The aim of the study was to assess the predisposing factors for joint contractures among patients with burn. The research question: what are the predisposing factors for joint contractures among patient with burn? Research design: A descriptive/exploratory research design was utilized to achieve the purpose of this study. Subjects: A convenience sample of 176 adult male and female burn patients diagnosed post burn contracture as a result of 2nd and / or 3rd degree burn injury admitted to the surgical wards and burn unit at one of the governmental university hospitals was recruited in the current study as the burn cases admission increase increased in the following three years $(2010,2011$, and 2012$)$ as $(405,543,487)$ respectively. The study sample calculated using a power analysis Tool: Burn assessment data sheet consists of two parts: 1- Demographic data sheet and 2- Predisposing factor assessment sheet through direct interview with patients. Results and conclusion: The study results concluded that the highest percent of the predisposing factors for joint contractures among patients with burn injury are (wound not healed on discharge, presence of signs of infection, no physical exercise after discharge, male, accidental burn injury, hospital not near, Rt.arm as a region of burn joint involved and no skin plastic surgery). Middle percent of them are (no health teaching about type of food, Lt. arm region of burn involved, home as a place of burn, married, rural area, limited movement for the affected joint, no application of joint support, educational level as diplome and no health teaching about correct joint positioning) followed by the lowest percent which are (2nd and 3rd degree burn injury, 20- as a percentage of burn injury, refuse to do physical exercise, no movement of the affected joint, Age $(18<30)$, flame burn and late starting of physical exercise. Recommendations: Developing a comprehensive treatment and rehabilitation program for those patients. All burn patients should receive adequate care to avoid post burn complication.
\end{abstract}

Key words: Burn, joint contracture, nursing role.

\section{INTRODUCTION}

Burn injuries are among the most devastating of all injuries and a major global public health problem. Burns are the fourth most common type of trauma worldwide, following traffic accidents, falls, and interpersonal violence. Approximately $90 \%$ of burns occur in low to middle income countries, regions that generally lack the 
necessary infrastructure to decrease the incidence and severity of burns. (Peck, 2012). Burns can leave a patient with severely devastating and deforming contractures, which can lead to significant disability when left unmanaged. A contracture is a tightening of skin that may influence the underlying muscles and tendons limiting the joint mobility. Contractures develop when normal elastic connective tissues are replaced with inelastic fibrous tissue. This makes the tissue resistant to stretching and prevents normal movements of the affected area. Physical therapeutic measures can aid in controlling burn scar contracture. If these treatments do not control the effect of contractures, surgical intervention may be obliged. (Babu, Shanmuganathan \& Prabhu, 2010). The aims of burn rehabilitation are to reduce the adverse effects caused by the injury in terms of maintaining range of movement, minimizing contracture development and impact of scarring, maximizing functional ability, maximizing psychological wellbeing and also maximizing social integration. (Procter, 2010). Anti-contracture positioning and splinting must begin from day one and may continue for many months post-injury. It applies to all patients whether they have been skin grafted or not. Positioning is imperative to influence tissue length by limiting or inhibiting loss of range of motion secondary to the development of scar tissue. Patients rest in a position of comfort; this is generally a position of flexion and also the position of joint contracture. Wounds start the healing process almost as soon as they occur and a major part of this process is wound contracture. (Procter, 2010). The nurse works closely with occupational therapist to identify the rehabilitative needs of the burn clients and the nurse oversees the total care of the patient, coordinating activities with other multidisciplinary team. (Fauerbach, 2010).

\section{Aim of The Study}

The aim of the current study was to assess the predisposing factors for joint contracture among patients with burn.

\section{Research Questions}

To fulfill the first aim of the study the following research question was formulated:

What are the predisposing factors for joint contractures among patients with burn?

\section{Subject And Methods}

\section{Research design:}

A descriptive exploratory research design was utilized in the study.

\section{Setting:}

The study was conducted the burn and all surgical units at one of the governmental university hospital which consist of 2 side for male and female patients with about 40 bed capacity each side. The researcher was allowed to use the mentioned wards for participant interview.

\section{Subjects:}

A convenient sample of 176 adult male and female surgical patients diagnosed with post burn contracture as a result of $2 \mathrm{nd}$ or $3 \mathrm{rd}$ degree of burn.

\section{Tools of data collection:}

The data of this study was collected using assessment data sheet which consist of part 1 cover demographic data and part 2 cover the predisposing factors for joint contracture. 


\section{Methods of data collection:}

Consent to conduct the study was taking from the vice dean of Higher Education and Research at Faculty of Nursing, Cairo University, and the approval of ethical committee, and an approval letter from the hospital administration. The tools were translated into Arabic language and reviewed by jury consisted of five professors in medical surgical nursing to be tested for its content validity.

A pilot study was carried out on (10\%) of sample to test the applicability and clarity of the questions, also to estimate the needed time to fill it, and to make sure that items are fully understood. The potential subjects were interviewed individually face to face to explain the nature and purpose of the current study. A written consent form was obtained from each prospective participant who agreed to participate in the study. The data of this study was collected using assessment data sheet. It was constructed by the researcher after reviewing the literature of the various aspects of the related issue. Data collected about demographic data and the predisposing factors assessment sheet. The data collection phase took 11 months from May 2013 to March 2014.

\section{Ethical Considerations}

Before commencing the study, ethical approval was granted from the research ethics committee in which the study took place. The researchers ensured that the correct procedures were undertaken concerning informed consent, autonomy, anonymity and the maintenance of confidentiality.

\section{Statistical analysis: -}

Upon completion of data collection through the previously mentioned tool, data was computed and analyzed. Data analyses were carried out using the Statistical Package for Social Sciences (SPSS).All data entries were checked for accuracy against the original raw data of each patient by the investigator. A probability level of 0.01 and 0.05 was adopted as the level of significance for all statistical tests done. The following statistical tests were used according to the number of participant patients: (a) Frequency and percentage distribution for all variables (b) Mean and Standard Deviation utilized.

\section{Results:}

Table (1) illustrates that $(40.9 \%$ and $39.2 \%$ ) of the study subjects their age between $18<30$ and $30<40$ years respectively and $(19.9 \%)$ was $40 \leq 50$ years old. $(77.8 \%)$ of them were males, whereas $(22.2 \%)$ were females. As regards to marital status $(59.7 \%)$ was married and $(35.2 \%)$ single. Regarding educational level, secondary / deplome education and primary / preparatory were $(56.3 \%$ and $21.6 \%)$ respectively. Also patients who can read and write, cannot read and write, college and post graduate were $(10.2 \%, 8.5 \%$ and $3.4 \%)$ respectively. As regards to patient's occupation, $(31.3 \%)$ of the study subjects were labor hand/workers, whereas $(22.7 \%)$ occupying as farmers, (19.3\%) were employee, (18.8\%) were house wife and $(8.0 \%)$ doesn't work. In relation to residence, $(58.0 \%)$ of the study subjects were rural residents whereas the urban represent $(42.0 \%)$.

Table (2) reveals that $(76.7 \%)$ of the study subjects don't have chronic disease, whereas $(23.3 \%)$ of the study subjects have chronic disease. These diseases were hepatic, diabetic, cardiac and renal represent $(9.1 \%$, $9.1 \%, 3.4 \%$ and $1.7 \%$ ) respectively.

Table (3) Shows that (40.3\%) of the study subject the burn injury caused by direct flame followed by chemical substances, boiled fat, vapor and electric as (19.9\%, $16.5 \%, 9.1 \%, 4.5 \%)$ respectively. Regarding the reason of the burn injury $(72.7 \%)$ of the study subjects from accidents, crimes 
$(26.1 \%)$ and suicide was $(1.1 \%)$. As regards to the Place of the Burn Injury $(60.8 \%)$ of the study subject the incident happened at home, on the street $(33.5 \%)$ and at work $(5.7 \%)$. Regarding the place if it's near of the hospital or no $(72.2 \%)$ of the study subjects the place not near to the hospital. Regarding time spending to arrive to the hospital (40.9\%) of the study subjects take $45 \mathrm{~min}$. and $60 \mathrm{~min}$, $30 \mathrm{~min}$., and $15 \mathrm{~min}$. whereas $(29.5 \%, 20.5 \%$ and $9.1 \%$ ) respectively.

Tables (4) reveal that $(90.9 \%)$ of the study subject received first aid management after the incident. Among them (77.3\%) received at the place of incident, while (13.6\%) received care in the hospital. As regards to type of first aid $(55.1 \%)$ of the study subject were used cold water while $(24.4 \%)$ and $(11.4 \%)$ used soaked cover and cold water respectively.

Table (5) reveals that among those who had injury the high percent including chest, head, Rt.arm, Abdomen, Lt. arm and face as (79.5 ,76.1\%, 71.6\%, 64.8\%, 61.9\% and $56.3 \%$ ) respectively. But the least percent including Rt. leg, Lt.leg and back as (16.5\%, $6.8 \%$ and $4 \%$ ) respectively.

Table (6) illustrated that percentage of burn injury among the study subject were between $10 \%$ to less $50 \%$. But the highest $\%$ (43.8) between $20 \%$ to less than $30 \%$ followed by $(30.7 \%)$ between $30 \%$ to less than $40 \%$. (44.9\%) of the study subject was their degree of burn was 2nd and 3rd degree, while a nearly \% (29 \& 26.3) were 2 nd and 3 rd degree respectively.

Table (7) shows that frequency of the dressing $(68.8 \%)$ did it every 2 days while $(31.3 \%)$ every day. (57.4\%) did regular dressing while $(42.6 \%)$ were not doing dressing regularly. Regarding signs of infection $(100 \%)$ of the study subject had high temperature while $(81.8 \%)$ of them had secretions from the wound followed by bad odor as $(64.8 \%)$. (63.1\%) of the study subjects No one tell them about type of food and they are eating the ordinary hospital food. And (36.9\%) they are informed about the food rich in protein. 
Assessment of Predisposing Factors for Joint Contracture among Patients with Burs at One of the Governmental University Hospitals

Table (1): Frequency and Percentage Distribution of Demographic Data among Study Subjects $(n=176)$.

\begin{tabular}{|c|c|c|}
\hline Variables & $\mathbf{N}$ & $\%$ \\
\hline $\begin{array}{l}\text { Age /years } \\
\qquad \begin{aligned} 18-- \\
30-- \\
40 \leq 50\end{aligned}\end{array}$ & $\begin{array}{l}72 \\
69 \\
35\end{array}$ & $\begin{array}{l}40.9 \\
39.2 \\
19.9\end{array}$ \\
\hline$\overline{\mathbf{X}}+\mathbf{S D}$ & & \\
\hline $\begin{array}{ll}\text { Gender } & \\
& \text { Male } \\
& \text { Female }\end{array}$ & $\begin{array}{c}137 \\
39\end{array}$ & $\begin{array}{l}77.8 \\
22.2\end{array}$ \\
\hline $\begin{array}{cl}\text { Marital Status } \\
& \text { Single } \\
\text { Married } \\
\text { Divorced }\end{array}$ & $\begin{array}{c}62 \\
105 \\
9\end{array}$ & $\begin{array}{c}35.2 \\
59.7 \\
5.1\end{array}$ \\
\hline $\begin{array}{l}\text { Educational level } \\
\text { Can't read or write } \\
\text { Read and write } \\
\text { Primary/preparatory school } \\
\text { Secondary/diplome } \\
\text { College/ post graduate }\end{array}$ & $\begin{array}{c}15 \\
18 \\
38 \\
99 \\
6\end{array}$ & $\begin{array}{c}8.5 \\
10.2 \\
21.6 \\
56.3 \\
3.4\end{array}$ \\
\hline $\begin{array}{l}\text { Occupation } \\
\text { Doesn't work } \\
\text { House wife } \\
\text { Farmer } \\
\text { Labor hand/Worker } \\
\text { Emplovee }\end{array}$ & $\begin{array}{l}14 \\
33 \\
40 \\
55 \\
34\end{array}$ & $\begin{array}{c}8.0 \\
18.8 \\
22.7 \\
31.3 \\
19.3\end{array}$ \\
\hline $\begin{array}{c}\text { Residence } \\
\text { Rural } \\
\text { Urban }\end{array}$ & $\begin{array}{c}102 \\
74\end{array}$ & $\begin{array}{l}58.0 \\
42.0\end{array}$ \\
\hline
\end{tabular}

Table (2): Frequency and Percentage Distribution of chronic disease among study subjects. $(n=176)$.

\begin{tabular}{|c|c|c|}
\hline Variables & N & \% \\
\hline Presence of chronic diseases & & \\
Yes & 41 & 23.3 \\
No & 135 & 76.7 \\
\hline Among, Yes & & \\
Hepatic & 16 & 9.1 \\
Diabetic & 16 & 9.1 \\
Cardiac & 6 & 3.4 \\
Renal & 3 & 1.7 \\
\hline
\end{tabular}


Table (3): Frequency and Percentage Distribution of methods, reasons and place of burn injury and time spending to arrive the hospital $(n=176)$.

\begin{tabular}{|c|c|c|}
\hline Variables & $\mathbf{N}$ & $\%$ \\
\hline \multicolumn{3}{|l|}{ Methods of Burn } \\
\hline Direct flame & 71 & 40.3 \\
\hline Chemical substances & 35 & 19.9 \\
\hline Boiled fats & 29 & 16.5 \\
\hline Boiled water & 17 & 9.7 \\
\hline Vapor & 16 & 9.1 \\
\hline Electric & 8 & 4.5 \\
\hline \multicolumn{3}{|l|}{ Reason Behind Burn Injury } \\
\hline Accident & 128 & 72.7 \\
\hline Criminal & 46 & 26.1 \\
\hline Suicidal & 2 & 1.1 \\
\hline \multicolumn{3}{|l|}{ Place of Burn Injury } \\
\hline Home & 107 & 60.8 \\
\hline Street & 59 & 33.5 \\
\hline Work & 10 & 5.7 \\
\hline \multicolumn{3}{|c|}{ Does the Place of Burn was near the hospital? } \\
\hline No & 127 & 72.7 \\
\hline Yes & 49 & 27.8 \\
\hline \multicolumn{3}{|c|}{ Time Spending to Arrive the Hospital } \\
\hline$\leq 60$ minutes & 52 & 29.5 \\
\hline$\leq 45$ minutes & 72 & 40.9 \\
\hline$\leq \mathbf{3 0}$ minutes & 36 & 20.5 \\
\hline$\leq 15$ minutes & 16 & 9.1 \\
\hline
\end{tabular}

Table (4): Frequency and Percentage Distribution of first aid management among the study subject. $(\mathbf{n}=176)$.

\begin{tabular}{|l|c|c|}
\hline \multicolumn{1}{|c|}{ Variables } & $\mathbf{N}$ & $\%$ \\
\hline $\begin{array}{l}\text { First aid management } \\
\text { No }\end{array}$ & 16 & \\
Yes & 160 & 90.9 \\
Among yes, Where? & & \\
& & \\
$\quad$ At hospital & 24 & 13.6 \\
$\quad$ At place of burn & 136 & 77.3 \\
& & \\
Types of first aid & & \\
Wash with solution & 20 & 11.4 \\
Cold water & & 55.1 \\
Soaked cover & 97 & 24.4 \\
\hline
\end{tabular}


Assessment of Predisposing Factors for Joint Contracture among Patients with Burs at One of the Governmental University Hospitals

Table (5): Frequency and Percentage Distribution of regions of burn injury among study subject. $(\mathrm{n}=176)$.

\begin{tabular}{|l|c|c|}
\hline Variables * & \multicolumn{2}{|c|}{ Yes } \\
\cline { 2 - 3 } Chest & N & $\%$ \\
Head & 140 & 79.5 \\
Rt.arm & 134 & 76.1 \\
Abdomen & 126 & 71.6 \\
Lt.arm & 114 & 64.8 \\
Face & 109 & 61.9 \\
Rt.leg & 99 & 56.3 \\
Lt.leg & 29 & 16.5 \\
Back & 12 & 6.8 \\
\hline
\end{tabular}

*Total No. not mutually exclusive.

Table (6): Frequency and Percentage Distribution of percentage and degree of burn injury among the study subject $(n=176)$.

\begin{tabular}{|c|l|l|}
\hline Variables & N & \% \\
\hline Percentage of burn injury & & \\
$\mathbf{1 0}-$ & 43 & 24.4 \\
$\mathbf{2 0}-$ & 77 & 43.8 \\
$\mathbf{3 0}-$ & 54 & 30.7 \\
$\mathbf{4 0}-\mathbf{4 9}$ & & 1.1 \\
Degree of burn injury & & \\
2nd Degree & 51 & 29 \\
3rd Degree & 46 & 26.1 \\
2nd \& 3rd Degree & 79 & 44.9 \\
\hline
\end{tabular}


Table (7): Frequency and Percentage Distribution of burn wound dressing, signs of infection and health teaching about type of food among the study subject $(n=176)$.

\begin{tabular}{|c|c|c|}
\hline Variables & $\mathbf{N}$ & $\%$ \\
\hline $\begin{array}{c}\text { Dressing frequency } \\
\text { Every day } \\
\text { Every } 2 \text { days }\end{array}$ & $\begin{array}{l}55 \\
121\end{array}$ & $\begin{array}{l}31.3 \\
68.8\end{array}$ \\
\hline $\begin{array}{l}\text { Regular Dressing } \\
\text { No } \\
\text { Yes }\end{array}$ & $\begin{array}{l}75 \\
101\end{array}$ & $\begin{array}{l}42.6 \\
57.4\end{array}$ \\
\hline $\begin{array}{c}\text { Signs of infection } \\
\text { High temperature } \\
\text { Yes } \\
\text { Secretion } \\
\text { Yes } \\
\text { Bad odor } \\
\text { Yes }\end{array}$ & $\begin{array}{l}176 \\
144 \\
114\end{array}$ & $\begin{array}{l}100 \\
81.8 \\
64.8\end{array}$ \\
\hline $\begin{array}{c}\text { health teaching about type food } \\
\text { Yes } \\
\text { No }\end{array}$ & $\begin{array}{l}65 \\
111\end{array}$ & $\begin{array}{l}36.9 \\
63.1\end{array}$ \\
\hline $\begin{array}{l}\text { if yes what are the type of food } \\
\text { Food rich in protein }\end{array}$ & 65 & 36.9 \\
\hline
\end{tabular}

\section{Discussion}

Contractures develop rapidly in the burned patients who are not receiving early and sufficient care. Once these contractures developed the patient will experience unnecessary additional frustrating problems in all aspect of their life, these problems may be social, personnel or economical. Contractures could be prevented through proper positioning of burned body segments supplemented with proper splints if needed and compromises early active exercises as early as possible. (Linton, 2012).

Most of burn patients who develop joint contractures were less than thirty years old which represent one third of the study subject, who were in the most productive period of their life. Mean age of the present study was $32.7 \pm 7.9$ ranging from eighteen to fifty years old. This result may be explained from the researcher point of view by the fact that early adulthood is generally active and therefore they are exposed to hazardous situations at both work and home. The finding of the current study was in the same line with the study. (Mohamed, 2014) who reported that more than one third of the study subject their age less than thirty years old which constituted the highest percentage of total sample. In agreement with study. (Mohamed, 2010) who found that the majority age ranged between (18-30) years old.

This findings are similar to the study done by (Mistry, Pasisi, Chong, Stewart, \& She, 2010) who studied socioeconomic deprivation and burns, they founded that the rate of admissions to burn units are increased in proportion with diminishing economic status, as those with the least available resources are exposed to burn hazards such as lack of smoke detectors, cigarette smoking, 
household overcrowding and low educational level.

In relation to residence more than half of the study subject was living in rural areas and also one third of the study sample was workers. In the same line with study of (Ahmed, 2011) who reported that the majority of patients living in rural areas. Also study of (Elsherbiny, 2010) and study of (Ebrahim, 2009) confirming the previous findings that the patients in their studies indicated that they were employed. These results were supported by study of (Abd El Hamid, 2009) which found that the majority of patients with burn injury were workers. On other hand, the finding of the study of (Ying, 2010) reported that highest percentage of burn victims was not working. The majority of the present study subjects were unemployed and living with families because of lack of job opportunities and high level of job requirements.

As well, study (World Health organization, 2014) of burns and indicated that individuals living in low and middleincome countries (as in rural area) are at higher risk for burns than people living in high-income countries. Moreover study of (Shanker, Naik \& Powar, 2010) which studied epidemiological study of burn injuries admitted in two hospitals of North Karnataka were reported that most of the burn patients were from rural areas.

In relation to gender the study results revealed that more than two third of the study subject was male. In the same line with study of (Black \& Hawks, 2009) agreed that early adults with burn injuries are more likely to be male and in the 20to 40 age group. Also, study of (Hassan, 2008) found that the majority of patients were males who were exposed to occupational hazards. This could return back to Egyptian culture that male are responsible for earning life. Therefore they are more exposed to hazards than females.
On the other hand, these findings not matching with study of (Dyer \& Roberts, 2010) in which the most common burn accident occurred at home for females. This could be explained in the light of their primary responsibility of caring for all family members. In addition, the finding in study of (Ahmed, 2011) stated that higher ratio of female burn patients was more than male. Results in this study indicated that women were at high risk of burn injury. On the same line with the finding of the study of (Mezezwa, Jonsson, Aberg \& Salemark, 2010) explained that women lead traditionally to cooking as they were burn during the usual times of preparing meals. While in study of (Alaa Eldein, 2010) reported that the burn accident occurs in equal distribution among both sexes (males and females).

The current study revealed that about three quarters of the study subject were exposed to accidental incidence which was very high. On the same line with the finding of the study of (Kypri, Chalmars, Angedly \& Wright 2011) which reported that the major causative agent of burn injuries in their studied sample was flame and majority of pattern of burn injury was accidental burn. In addition according to the study of (American Burn Association, 2012) more than 2.5 million people in United States experience accidental, thermal injury each year.

The current study revealed that more than twenty five percent of total body surface area (TBSA) was affected among more than one quarter of the studied subject, where as forty five percent with second and third degree of burn. These results were in the same line with study of (Mohamed, 2010) in which reported that the highest percentage of burn patients had burn injury covering more than twenty five percent TBSA. Study of (Hassan, 2008) explained that this could be due to delay in transferring the patient Immediately after burn injury to burn center, or due to use some public substances which hinder the care provided to the patient and 
delay in providing first aid or using correct modalities which lead to transferring the minor burn injury to moderate or severe burn injury. From the researcher point of view these findings may be explained that the patients with severe burn injury could expose to increase their potential lifelong scars disfigurements, deformity and contracture. Therefore could affect the ability to achieve their role in society.

The findings of the present study clarified that the upper limbs are most common location of burns and chest followed by abdomen, face, head and lower limbs in burn injury. On the same line with study of (Mohamed, 2014) which explained that, hand burn generally evoke fears related to functional independence, whereas burn face related to loss of identity, moreover, faced and hand burns are the most difficulty burns to reconcile these body parts represent. In study of (Ahmed, 2011) mentioned that the patients, who had burn injuries in the visible sites as hands and face, are the majority of his studied which had low self-image. While, study of (Mezezwa, Jonsson, Aberg, \& Salemark, 2010) found in a study performed on burned patient that the anatomical sites which is the most frequently burn were the trunk, head, and the lower extremities. Study of (Fauerbach, 2010) and (Munnoch, 2010) the results are in agreement that the most common location for burns was hands, fore arms, neck, chest and thighs.

The researcher delineate from the above finding and discussion that the highest $\%$ of the predisposing factors for joint contractures among patient with burn injury are (wound not healed on discharge, presence of signs of infection, no physical exercise after discharge, male, accidental burn injury, hospital not near, Rt.arm as a region of burn joint involved and no skin plastic surgery). Middle \% of them are (no health teaching about type of food, no instruction about importance of physical therapy, lt. arm region of burn involved, home as a place of burn, married, rural area, limited movement for the affected joint, no application of joint support, educational level as diplome and no health teaching about correct joint positioning) followed by the lowest \% which are (2nd and 3rd degree burn injury, 20- as a percentage of burn injury, refuse to do physical exercise, no movement of the affected joint, Age $(18<$ 30 ), flame burn and late starting of physical exercise).

\section{Recommendations}

In the light of the findings of the present study, the following are recommended:

\section{patients:}

Recommendations related to the

- All burn patients should receive adequate care to avoid post burn complication.

- Health education regarding the importance of physical exercise, range of motion and healthy diet.

- Provide community based education related to burn injury.

\section{Recommendation related to} education, nursing clinicians and health team:

- Encourage students to conduct community health education for burn prevention and first aid management.

- Incorporate methods to develop nursing protocols to avoid post burn complications especially joint contractures.

- Planning for education sessions for medical team and hospital administrators to raise awareness about post burn contractures as a serious. 
- Developing a comprehensive treatment and rehabilitation program to avoid joint contractures which consider as one of the most common complication of burn injury.

- Protocol of wound care should be standardized and used for measurement of quality of wound care.

- Protocol of physical exercise and range of motion should be conducted to avoid the complication of burn injury.

\section{Recommendations related to health administrators and community leaders:}

- Develop program for burn prevention awareness program for community to increase the people knowledge using pamphlets, rollups and Extra Safety Measure in Work place to avoid burn injury from the beginning.

- Encouragement of the media (Television, radio, and newspaper) to raise awareness for burn prevention and burn complication through different programs and media campaigns.

\section{Recommendations related to researchers:}

- More studies need to be conducted to assess and identify more variables lead to joint contractures.

- Replication of the study on a larger probability sample selected from different geographical areas in Egypt is recommended to obtain more generalizable data.

\section{References}

Abd El Hamid, A. (2009). Conventional occlusive dressing versus polythene gloving on second degree burned hands. Unpublished master thesis.
Faculty of nursing. Alexandria University.

Ahmed, G.E. (2011). Impact of burn injuries on self-image of adolescents, unpublished master thesis, faculty of nursing, Cairo University.

Alaa, Eldein, (2010) Determination of physical rehabilitation nursing activities for superficially. Moderate burns for the prevention of contracture deformity.

American Burn Association 2012 , supplement to journal of burn care \& research March 2012 volume 33, number 2 Washington, USA.

Babu,M., Shanmuganathan,N,. prabhu,K,.(2010).wound healing in burns :JAYPEE. sarabahi,S,.Tiwari,VK,.Goel,A,.Gupta,LC ..(2010). Principles and Practice of Burn Care.1st ed.PP26 Available@http://www.jaypeedigital.com /ChapterSpecific.aspx .id=978818448809 $8 \&$ sno $=\mathrm{J} 6 \mathrm{FN}+\mathrm{UZ3U} \mathrm{U}$ U\%3d\&sr

Black, M.J. and Hawks, H.J. (2009). Medical surgical nursing management of clients with burn injury, 7th edition, Elsevier, Saunders, USA, pp 1433:1434.

Dyer, C. and Reborts, D. (2010). Thermal trauma. Nursing clinics of north America.

Ebrahim, A. (2009). conventional occlusive dressing versus polythene gloving on second degree burned hands. Unpublished master thesis, faculty of nursing, Alexandria University. P.65.

El Sherbiny, O. (2010). Quality of life for adult patients with severe burn injury. Unpublished master thesis, faculty of nursing, Alexandria University.pp.6068. 
Fauerbach, J.A. (2010). Anorm-based injury into the influence of burn size and distress on recovery of physical and psychological function. Burn care rehabilitation, 6th edition. Mosby, marck. pp. 504.

Hassan, M.S. (2008). Burn care educational program for nurses' professional development, doctorate thesis, unpublished thesis, and faculty of nursing, Ain shams university.

Kypri, K., Chalmars, D.L., Angedly, T., and Wright, C. (2011). Adult injury morbidity in new Zealand, journal of adult health. pp. 227- 234.

Linton,A,. (2012). Introduction to medical surgical nursing.5th ed. Elsevier. Library of congress. USA. PP:1199.

Mezezwa, S., Jonsson, K., Aberg, M. \& Salemark, L. (2010). a prospective study of suicidal burns admitted to the harara burns unit, burns, aug. pp. 460-464.

Mistry, R.M., Pasisi, L., Chong, S., Stewart, J. \& She, R.B. (2010). Socioeconomic Deprivation and Burns. Burns; 36 (3), 403-8.

Mohamed, R. (2010). Assessment of burned patients' needs in banha teaching hospital. Master Degree. Medical surgical nursing .PP. 59-66.

Mohamed, S. (2014). Effect of rehabilitation program on burned patients in banha teaching hospital. Doctorate thesis. Medical surgical nursing .pp. 107-110.

Munnoch, D. (2010). Burn wound infections, e-medicine journal. Available at: http://emedicine.medscape.com. At 01/10/2015.

Peck,M.D.(2012). Epidemiology of burn injuries globally. Wolters kluwerhealth.Available@http://www.upto date.com/contents/epidemiology-of-burninjuries-globallylast updated: 8-2012.

Polit,D.F.\&Beck,C.T.(2012).nursing research; generating and assessing evidence for nursing practice. 9th ed.wolters kluwer.india.pp:547.

Procter,F.(2010). Rehabilitation of the burn patient. Indian J Plast surg.43.No.(3).101113.Available@http:// www.ncbi.nlm.nih.gov/pmc/articles/PMC 3038404/27-sep-2010.

Shankar, G., Naik, V. A., \& Powar, R. (2010). Epidemiolgical Study of Burn Injuries Admitted in Two Hospitals of North Karnataka. Indian Journal of Community Medicine: Official Publication of Indian Association of Preventive \& Social Medicine, 35(4), 509-512. http://doi.org/10.4103/09700218.74363 .

Vaishali, T,.(2011). Hand Book of nursing research and biostatistics. 1sted. Jaypee. New Delhi. India. PP: 129.

World Health Organization (2012). Burns. Available

at: http://www.who.int/mediacentre/fac tsheets.

World Health Organization (2014). WHO launches new document on burn prevention and care. Available at: http://www.who.int/violence/media/news

Ying, S.Y. (2010). Suicides burns in Hong Kong. Burns. Chines, (16) pp: 125- 127. 